WASHINGTON, D.C.-The U.S. Department of Defense (DoD) invited public comment in August on an impending comprehensive environmental impact statement for its biological defense research program, much of which involves applications of biotechnology to biological warfare (BW). Only a handful of people showed up at the "scoping" meeting, however, and in general their attitudes seemed to reflect more a distrust for DoD's program than a concern for the environment.

DoD's research is conducted in many facilities across the country, with a sizable fraction of the work being done under contract at universities or in small companies. The requirement for a program-wide environmental impact statement is part of the settlement of a lawsuit brought last year by Jeremy Rifkin and his Foundation on Economic Trends (Washington, D.C.) along with Neil Levitt, a former senior scientist with the U.S. Army Medical Research Institute of Infectious Diseases at Fort Detrick, MD. DoD expects its contractor, Battelle Laboratories' Columbus Division, to prepare a draft environmental impact statement by May 1988, when it will be circulated for public review and comment. (Although the period for making "scoping" comments officially ended in August, interested parties may obtain further information by writing: U.S. Army Medical Research and Development Command, ATTN: Mr. Charles Dasey, SGRD-PA, Ft. Detrick, MD 21701-5012.)

Rifkin and his associates, as well as other critics, insist that the new methods of biotechnology have radically changed the rules-and thereby raised the stakes —of BW research. In claiming that biotechnology favors "offensive rather than defensive" research on biological warfare agents, however, critics seem to imply that DoD's program serves a more sinister purpose than the department acknowledges-or, for that matter, than is permitted by international treaty. For instance, Nachama Wilker, who represents the Bostonbased Committee for Responsible Genetics, says that DoD's program "destabilizes the Biological Weapons Convention of $1972 \ldots$ and increases the risk of other countries working in this area." Thus she asserts that an environmental impact statement can "only reflect one outcome: the Biological Defense Program should not go ahead."
Nonetheless, the federal judge who agreed that DoD should formulate an environmental impact statement also specified that the program could continue while the statement is being completed. Much of the work involves research on vaccines against exotic diseases and developing rugged instruments, such as bioprobes, for use in the battlefield to detect toxins or pathogens.
Ironically, one of the most incisive comments regarding biological defense programs was made during the annual meeting of the Society for Industrial Microbiology. This conference was held in nearby Baltimore during the same week as DoD's scoping meeting. "Sure, we take DoD money to develop bioprobes," said one researcher. "It means fewer bombs." -Jeffrey L. Fox

\title{
haRNESSING ALFALFA'S DEFENSES
}

\author{
IMAGE \\ UNAVAILABLE FOR \\ COPYRIGHT \\ REASONS
}

Plants may not have an immune system, but they do have a way to protect themselves against microbial pathogens. When 2-3-week-old alfalfa plants are sprayed with a suspension of spores of the pathogenic fungus Calletotrichum trifolii, they become resistant to infection for five days. Mature plants, which can be inoculated via the stems or leaves, also become resistant. When under attack, a plant produces phytoalexins (toxins) at the site of the injury in response to fungal elicitors (largely unidentified biochemically). According to Nichole O'Neill, a plant pathologist with the United States Department of Agriculture's Agricultural Research Service (Beltsville, MD), "No one understands how this really works. Once the signal is produced, the plant is resistant no matter where it is attacked." The response appears to be controlled by a single gene. O'Neill's colleague, C. Jacyn Baker, is constructing a cDNA library for resistant and susceptible plants; subtracting the differences should lead them to identifying the gene. The ultimate goal is to be able to trigger a plant's defense mechanism artificially; it may even be possible to genetically engineer plants with built-in defenses, concludes ONeill. 